Research Paper

\title{
An Examination of Effective Strategies for Reducing Learner Language Anxiety through Quasi-experimental Design
}

SAtomi Fuji

Corresponding author: satomi.321@outlook.jp

Hokkaido University

Hokkaido, Japan

\section{About the author}

Satomi Fujii received her Ph. D. from Graduate School of International Media, Communication, and Tourism Studies, Hokkaido University, Japan. She has years of experience in teaching English at high school, vocational school and university. She is currently a researcher at Hokkaido University. Her research interests include language anxiety, willingness to communicate (WTC), individual factors, and EFL teaching. 


\section{Abstract}

The negative impact of anxiety in learning a second or foreign language has been demonstrated in a number of studies over the past few decades. It is important to investigate ways of reducing such anxiety as empirical studies have shown that language anxiety negatively affects the language performance of learners. In this study, classroom intervention strategies for reducing language anxiety were implemented, and the effectiveness of the anxiety-reducing strategies was examined. The study was designed to ascertain: 1) which areas of the language anxiety were decreased due to intervention, 2) which strategies were considered the most effective in reducing language anxiety by learners, and 3) how the learners perceived the anxiety-reducing strategies. Participants were two groups of students from different universities in Japan, consisting of the experimental group $(N=50)$ and control group $(N=32)$. Questionnaire surveys were conducted before and after the intervention, with both the experimental and control groups. As a result, anxiety-reducing strategies were effective in reducing learner communication apprehension. Effective strategies for reducing language anxiety were found to be: making presentations in small groups instead of making presentations individually, and doing pair work and group work in class. From the responses to the open-ended questionnaire, learner perceptions of the strategies were found to be generally positive.

Keywords:Foreign Language Anxiety, Intervention Study, Communication Apprehension, Learner Perceptions, EFL classrooms in Japan

\section{Introduction}

Foreign language anxiety is known as one of the affective factors which influence learners in foreign language classroom situations. In recent years, this particular psychological construct has received more and more attention in the field of Second Language Acquisition (SLA) studies (e.g., Alsowat, 2016; Alrabai, 2015; Gkonou, 2017; Horwitz, 2017). This worldwide trend to investigate learners' language anxiety seems to reveal the changing roles of teachers in foreign language classrooms. In other words, teachers are trying to teach the learners in a more supportive manner, rather than being an authority figure in the class.

MacIntyre and Gardner (1994) define language anxiety as: "the feeling of tension and apprehension specifically associated with second or foreign language contexts, including speaking, listening, and learning" (p.284). Traditionally, a negative relationship between language anxiety and learners' performance has been discovered in most studies (e.g., Alrabai, 2014; Horwitz, Horwitz \& Cope, 1986). Although some researchers still insist on the facilitating aspect of language anxiety, the debilitating aspect of language anxiety is more widely accepted in the previous literature (MacIntyre, 2002). Moreover, Horwitz (2017) clearly emphasizes that the search for the advantages of language anxiety is a huge step backward. She insists that the idea of facilitative anxiety in language learning might be attractive to teachers when they find their students being unmotivated in classes, but this might be caused by the simple reason that that they are really anxious about language learning. It seems that too much learner anxiety is a pity solution to problems in language 
teaching, as in Horwitz's (2017) assertion, and it is surely essential that teachers should create a relaxing space with relatively low anxiety in classes if we take into account the feelings of highly anxious learners.

According to Horwitz (2013), previous studies suggest that approximately one-third of students usually feel moderately to strongly anxious about language learning. Language anxiety seems to be a serious problem for many students. Although there have been many studies focusing on learner foreign language anxiety up till now (e.g., Alsowat, 2016; Sparks \& Patton, 2013; Woodrow, 2006), studies focusing on how to reduce anxiety still need room for further investigation. In order to promote foreign language learning among learners, the alleviation of language anxiety is indispensable. Reducing learners' language anxiety is a significant issue, indeed, since the influence of language anxiety is quite salient in many cases. Alrabai (2015) contends that teachers should be regarded as the cornerstone during the implementation of the strategies for decreasing language anxiety among foreign language learners. It is thus important for teachers to recognize the anxious feelings of learners, as well as to play a key role in alleviating their anxiety in the class.

\section{Literature Review}

Concerning the extensive literature on language anxiety and its negative effects on language learning, studies focusing on how to minimize language anxiety deserve more attention. According to Horwitz et al. (1986), "educators have two options when dealing with anxious students: 1) they can help them to learn to cope with the existing anxiety-provoking situation, or 2) they can make the learning context less stressful (p.131)." Teachers are required to recognize learners' anxiety and help them cope with their anxious feelings through creating a supportive classroom atmosphere. In order to reduce learners' language anxiety in the foreign language learning, there are several measures that can be taken by both teachers and learners. These measures are potential strategies identified as effective in reducing learners' language anxiety (Fujii, 2015; Kondo \& Yang, 2004; Tsui, 1996). However, it is still questionable that to what extent, these strategies are effective. The following studies serves as an empirical investigation which aims to try out strategies for reducing anxiety through classroom intervention.

Nagahashi (2007) examined the effectiveness of cooperative learning in reducing EFL (English as a Foreign Language) learners' anxiety in Japan. Cooperative learning was integrating into the normal teaching activities as a twelve-week intervention. The targets were 38 university first-year students. The Foreign Language Classroom Anxiety Scale (FLCAS; Horwitz et al., 1986) was distributed to learners before and after the intervention. As a result, cooperative learning was effective in reducing learners' anxiety, as students' apprehension of failure in communication decreased significantly through the intervention. However, some of the factors leading to learners' anxiety were not able to be removed even after cooperative learning.

Tsiplakides and Keramida (2009) implemented a case study to examine the effectiveness of project work through collaborative learning in order to reduce anxiety. Participants of this study were 15 students in a secondary school in Greece. Observation, semi-structured interviews and group discussions were carried

out to find out the sources and reasons of their anxiety. Students were found to become more willing to participate in the speaking activities, and their English language performance was improved at the same 
time.

Alrabai (2015) conducted a quasi-experimental study to examine whether anxiety-reducing strategies would bring about positive changes in learners' anxiety levels. Participants of this study include 468 male EFL learners and 12 male teachers. Due to religious, social, and cultural restrictions, female participants were excluded from the study. The FLCAS (Horwitz et al., 1986) was used in order to assess the learners' anxiety levels. The practices of the teachers were rated A through classroom observation. The results of the intervention showed that learners' anxiety decreased significantly in the experimental group only. No changes were found with the control group.

These studies seek to figure out the effectiveness of interventions by measuring learners' anxiety or by judging through classroom observation. However, in each of these studies, several kinds of strategies were utilized together. Therefore, it is quite difficult to find out which strategies actually are effective for alleviating learners' language anxiety. Thus, it is of value to evaluate the effectiveness of anxiety-reducing strategies as individual items. In order to realize this goal, it is also important to inquire about the learners' perceptions of the anxiety-reducing strategies. This study investigates to what extent, such classroom interventions reduce the learners' anxious feelings in language learning, as well as how they perceive those strategies used as interventions to reduce their anxiety.

Accordingly, this study poses the following research questions:

RQ1: Which areas of EFL learners' anxiety decrease due to intervention?

$\mathrm{RQ2}$ : Which strategies do learners feel the most effective in reducing their anxiety?

RQ3: What are their perceptions of the anxiety-reducing strategies?

\section{Method}

\section{Participants}

Participants were divided into two groups, an experimental group $(\mathrm{N}=50$; male $=15$, female $=35)$ and a control group $(\mathrm{N}=32$; male $=25$, female $=7)$. Both groups were first-year undergraduate students from two national universities in Japan. Students in the experimental group were taking the English course held by the author. In the experimental class, anxiety-reducing strategies were utilized as a classroom intervention. Students in the control group were taking the English course held by another teacher. In the control class, no particular strategies for reducing anxiety were employed and teaching activities were the same as usual.

\section{Instruments}

The Foreign Language Classroom Anxiety Scale (FLCAS; Horwitz et al., 1986) was given to both the experimental and control groups twice, as the pre- and post-tests. The FLCAS contains 33 items of three categories, 1) communication apprehension, 2) test anxiety, and 3) fear of negative evaluation. Responses to the FLCAS were calculated as anxiety scores, and the total scores of each student were compared before 
and after the intervention. The Anxiety-reducing Strategy Scale (ARSS; Fujii, 2015) was assigned to the experimental group only, before and after the intervention. This scale consists of 15 items and aims to discover how effective each item is in decreasing students' language anxiety (e.g., "My anxiety decreases if I prepare thoroughly for the English test."). As a part of the post-test, an open-ended questionnaire was also assigned to the students in the experimental group. They were required to write down their perceptions of the interventions in class.

\section{Intervention}

The classroom interventions were carried out during the 15-week class period with the experimental group only. The anxiety-reducing strategies include: 1) pair work, 2) preparation before presentation, 3) presentation in pairs, 4) giving advice to students individually, and 5) maintaining a positive relationship between the teacher and the students. Pair work was frequently used in this class. The final presentation was also done in pairs. Students had two weeks to prepare for their presentation. They were also given 30 minutes for in-class practice just before the presentation. During the class, the teacher increased her interaction with the students and helped them individually as a tutor. The teacher were always friendly in class and showed respect to the students when providing comments on their work and performance. The control group did not include any of such interventions for reducing language anxiety. Since the students of the experimental and control groups were from two different universities, this study is a quasi-experimental study, which is designed with a non-equivalent control group.

\section{Data Analysis}

The data collected in this study were analyzed through both statistical and qualitative measures. The results of the FLCAS and the ARSS were computed by using IBM SPSS Statistics 22. First, a two-way repeated measures ANOVA (analysis of variance) was conducted for the total scores of the FLCAS and the scores of the three areas of learners' language anxiety. Then, a paired $t$-test was carried out for changes in students' opinions on the anxiety-reducing strategies. Finally, the data collected from the open-ended questionnaire were analyzed from a qualitative perspective using the Cycle Coding Method (Saldaña, 2009).

\section{Results}

\section{Changes in Students' Language Anxiety}

In order to check the changes in learners' anxiety at the start and end of the course, a two-way repeated measures ANOVA was performed based on the data of the experimental and control groups. Subscale scores were calculated regarding the three areas of language anxiety: 1) communication apprehension, 2) test anxiety, 3) fear of negative evaluation. The ANOVA shows statistically significant results for communication apprehension, with an $F$ ratio of $F(1,80)=4.375, p=.037$, indicating that items related to communication 
Table 1 Results of Repeated Measures ANOVA for Experimental ( $=50)$ and Control Groups $(\mathrm{N}=32)$

\begin{tabular}{|c|c|c|c|c|c|c|}
\hline \multirow[b]{2}{*}{ Anxiety Source } & \multicolumn{2}{|c|}{ Experimental } & \multicolumn{2}{|c|}{ Control } & \multirow[b]{2}{*}{$\begin{array}{c}F \\
(1,80)\end{array}$} & \multirow[b]{2}{*}{$\begin{array}{c}p \\
(\text { Anxiety } \times \text { Group })\end{array}$} \\
\hline & $\begin{array}{c}\text { Mean } \\
\text { (Pre-test) }\end{array}$ & $\begin{array}{c}\text { Mean } \\
\text { (Post-test) }\end{array}$ & $\begin{array}{c}\text { Mean } \\
\text { (Pre-test) }\end{array}$ & $\begin{array}{c}\text { Mean } \\
\text { (Post-test) }\end{array}$ & & \\
\hline $\begin{array}{l}\text { Communication } \\
\text { apprehension }\end{array}$ & 3.56 & 3.32 & 3.16 & 3.13 & 4.375 & .037 \\
\hline Test anxiety & 3.21 & 2.88 & 3.09 & 2.95 & 3.618 & .060 \\
\hline $\begin{array}{c}\text { Fear of negative } \\
\text { evaluation }\end{array}$ & 3.29 & 3.10 & 3.17 & 2.97 & 0.005 & .950 \\
\hline $\begin{array}{c}\text { Overall anxiety } \\
\text { (FLCAS total scores) }\end{array}$ & 110.22 & 101.38 & 103.34 & 99.41 & 3.367 & .070 \\
\hline
\end{tabular}

Table 2 Results of Simple Main Effects Test on Communication Apprehension

\begin{tabular}{|c|c|c|c|}
\hline & \multicolumn{3}{|c|}{$\begin{array}{c}\text { Communication Apprehension } \\
\text { Pre-test } \times \text { Post-test }\end{array}$} \\
\hline & $S D$ & $F$ & $p$ \\
\hline Experimental & .19 & .938 & .337 \\
\hline \multirow[t]{4}{*}{ Control } & .17 & 2.108 & .152 \\
\hline & \multicolumn{3}{|c|}{ Group } \\
\hline & \multicolumn{3}{|c|}{ Experimental $\times$ Control } \\
\hline & $S D$ & $F$ & $p$ \\
\hline Pre-test & .14 & 8.319 & .005 \\
\hline Post-test & .15 & 1.492 & .226 \\
\hline
\end{tabular}

apprehension decreased significantly among the learners in the experimental group. This suggests that the intervention in the experimental group was effective in decreasing learners' anxiety related to their speaking English. Test anxiety was close to the level of significance, with an interaction effect of $F(1,80)=3.618$, $p=.06$. The overall anxiety yielded an $F$ ratio of $F(1,80)=3.367, p=.07$.

As the result of communication apprehension yielded a significant interaction, the simple main effect was examined as follow-up tests. This analysis shows the difference between the two groups within each level of the independent variables. The detailed results are shown in Table 2.

As shown in Table 2, there was a significant difference in the $p$-value of the pre-test between the experimental and control groups. The significant difference in the pre-test scores shows that learners in the experimental group possessed a significantly higher degree of communication apprehension than the learners in the control group. Due to the intervention in class, learners' communication apprehension in the experimental group decreased considerably compared to the control group. Thus, conclusions could be made that strategies utilized in this study helped reduce learners' anxiety related to communication in class among 
Table 3 A Pre-Post Comparison of the Anxiety-reducing Strategy Scale (N=50)

\begin{tabular}{|c|c|c|c|c|c|c|c|}
\hline \multirow[b]{2}{*}{ Item } & \multicolumn{2}{|c|}{ Pre-Intervention } & & \multicolumn{2}{|c|}{ Post-Intervention } & \multirow[b]{2}{*}{$t$-value } & \multirow[b]{2}{*}{$p$-value } \\
\hline & $M$ & $S D$ & & $M$ & $S D$ & & \\
\hline $\begin{array}{l}\text { 1. My anxiety decreases if competition in the } \\
\text { classroom is reduced. }\end{array}$ & 3.64 & 1.08 & & 3.84 & .98 & -1.32 & .192 \\
\hline $\begin{array}{l}\text { 2. My anxiety decreases when I am told it is OK to } \\
\text { speak English with less than perfect performance. }\end{array}$ & 3.98 & .96 & & 4.18 & .77 & -1.40 & .168 \\
\hline $\begin{array}{l}\text { 3. If there are activities meeting various learning styles, } \\
\text { I do not feel anxious. }\end{array}$ & 4.06 & .77 & & 3.98 & .87 & 0.68 & .498 \\
\hline $\begin{array}{l}\text { 4. Speaking English in front of a small group is less stressful } \\
\text { than speaking to a large group. }\end{array}$ & 3.92 & 1.03 & & 4.06 & .96 & -1.00 & .322 \\
\hline $\begin{array}{l}\text { 5. I feel more relaxed when making presentations in } \\
\text { small groups than by myself. }\end{array}$ & 3.72 & .97 & & 4.14 & .88 & $-2.29 *$ & .026 \\
\hline $\begin{array}{l}\text { 6. If I have individual tutoring from the teacher, my } \\
\text { anxiety is reduced. }\end{array}$ & 3.88 & 1.02 & & 3.84 & .87 & 0.24 & .808 \\
\hline $\begin{array}{l}\text { 7. I feel relieved if I can discuss successful language } \\
\text { learning periodically with my teacher. }\end{array}$ & 3.92 & .92 & & 3.66 & .90 & 1.87 & .068 \\
\hline $\begin{array}{l}\text { 8. Doing more small group and pair work reduces my } \\
\text { anxiety. }\end{array}$ & 3.50 & 1.11 & & 4.02 & .87 & $-3.21 * *$ & .002 \\
\hline $\begin{array}{l}\text { 9. I feel relieved if the English test follows the same } \\
\text { format I was taught in class. }\end{array}$ & 4.52 & .58 & & 4.50 & .61 & 0.26 & .799 \\
\hline $\begin{array}{l}\text { 10. My anxiety decreases if I prepare thoroughly for } \\
\text { the English test. }\end{array}$ & 4.20 & .88 & & 4.36 & .75 & -1.21 & .231 \\
\hline $\begin{array}{l}\text { 11. I feel relieved if I am told being able to understand } \\
\text { is more important than being able to speak. }\end{array}$ & 3.28 & .88 & 3.26 & .90 & 0.13 & .896 & \\
\hline $\begin{array}{l}\text { 12. I feel relaxed if my pronunciation will not be } \\
\text { expected to be perfect. }\end{array}$ & 3.74 & .90 & & 3.82 & .98 & -0.46 & .647 \\
\hline $\begin{array}{l}\text { 13. I feel relieved if my classmates and I teach each } \\
\text { other. }\end{array}$ & 4.04 & .86 & & 4.00 & .83 & 0.30 & .766 \\
\hline $\begin{array}{l}\text { 14. My anxiety decreases if I work together with } \\
\text { classmates. }\end{array}$ & 3.88 & 1.04 & & 3.94 & .89 & -0.39 & .705 \\
\hline $\begin{array}{l}\text { 15. I feel relieved if my teacher cares for my own } \\
\text { anxiety. }\end{array}$ & 4.14 & .88 & & 4.22 & .74 & -0.60 & .552 \\
\hline
\end{tabular}

highly anxious learners. In-class communication tasks could become less stressful to highly anxious learners when anxiety-reducing strategies were adopted.

\section{Effective Strategies for Reducing Language Anxiety}

To ascertain the effectiveness of these anxiety-reducing strategies, learners' responses to the ARSS (Fujii, 2015) were compared between the pre- and post-tests. This survey instrument includes statements (15 items) concerning the strategies for reducing language anxiety. Students were required to answer all the 15 items on a five-point Likert scale, ranging from 1 (strongly disagree) to 5 (strongly agree). They should make 
evaluations based on their personal feelings whether the strategies implemented in the class were effective in reducing their language anxieties. The changes in the mean scores of the pre- and post-tests indicate the effectiveness of the strategies.

A paired $t$-test was performed based on the responses to each statement in the pre- and post-tests. Among the 15 items, two items showed a significant increase in their mean scores. Item 5, "I feel more relaxed when making presentations in small groups than by myself." showed a significant difference from the $t$-test $(t=-2.29, p<.05)$. Thus, it can be seen that students preferred to make presentations in small groups as opposed to by oneself. In addition, the mean score for Item 8, "Doing more small group and pair work reduces my anxiety." showed a significant difference $(t=-3.21, p<.01)$. Students have realized that group and pair work helped reduce their anxiety. These positive results indicate that cooperating with other classmates in class is an effective way to reduce the negative feelings of anxiety among students. There were no significant differences in the remaining items.

\section{Students' Perceptions of the Anxiety-Reducing Strategies}

As a part of the post-test, an open-ended questionnaire was distributed to students to obtain their comments on the effectiveness of the intervention strategies employed in the English class. The responses to the questionnaire were coded using the Cycle Coding Method (Saldaña, 2009). This method is useful for analyzing qualitative data through comparison of data, code, and categories back and forth in a cyclic process rather than a linear process. This coding method includes two main steps: the first cycle coding method and the second cycle coding method. The first cycle coding method refers to the simple and direct ways of coding the data. The second cycle coding method refers to the analytic process of the coded data, such as classifying, integrating, abstracting, conceptualizing and theory building. In this study, descriptive coding was chosen as the first cycle coding method, which summarizes texts into a key word or short phrase. As the second cycle coding method, pattern coding was used, which pulls together much information into a meaningful unit. This study utilizes these two methods because the combination of descriptive coding and pattern coding is recommended in Saldaña (2009). Through such processes, students' perceptions of the anxiety-reducing strategies are available.

The overall results are shown in Fig. 1. As a result of the intervention, terms such as "positive effects of pair work," "increase in confidence from preparation," "benefits of pair presentation," "importance of individual support," and "positive teacher-student relations" emerged from the learners' responses. "Lingering fear of public speaking" also emerged, despite students made preparations before their presentation.

As for the pair work and group work, students felt less stressed and more fulfilled when working with their classmates. This is a typical reaction in class and represents their "positive affect." Improvement in their English performance and learning skills is expressed though "development in English." Supporting each other means that they were able to share answers, which is labeled as "mutual cooperation." These are the positive feelings students gained through working together, thus they can be summarized as the "positive effects of pair work" (Fig. 2).

suggest that most of the learners felt they could do better through "enough practice," in addition to 


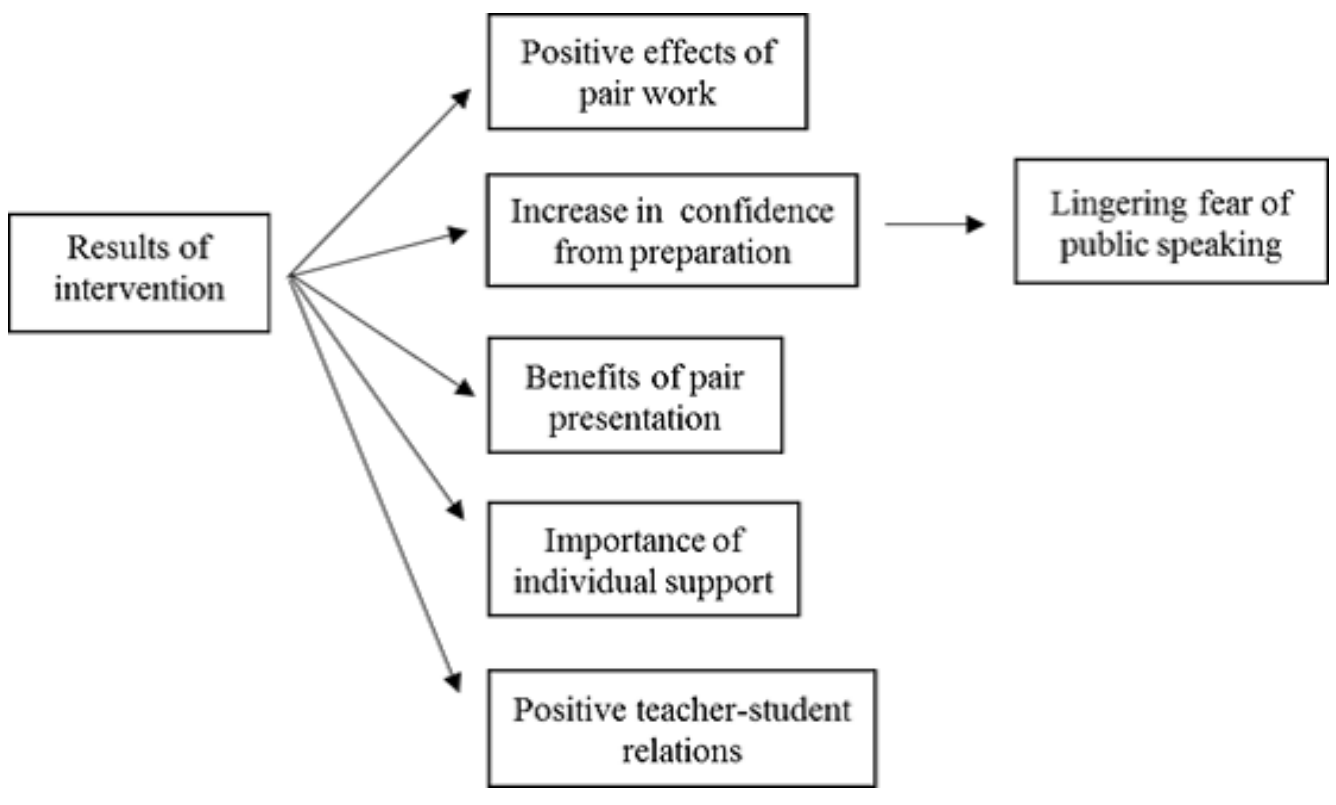

Fig. 1 Overall Results of Open-ended Questionnaire Data Coded through Pattern Coding. Signs $(\rightarrow)$ in this chart indicate the interrelation of pattern codes.

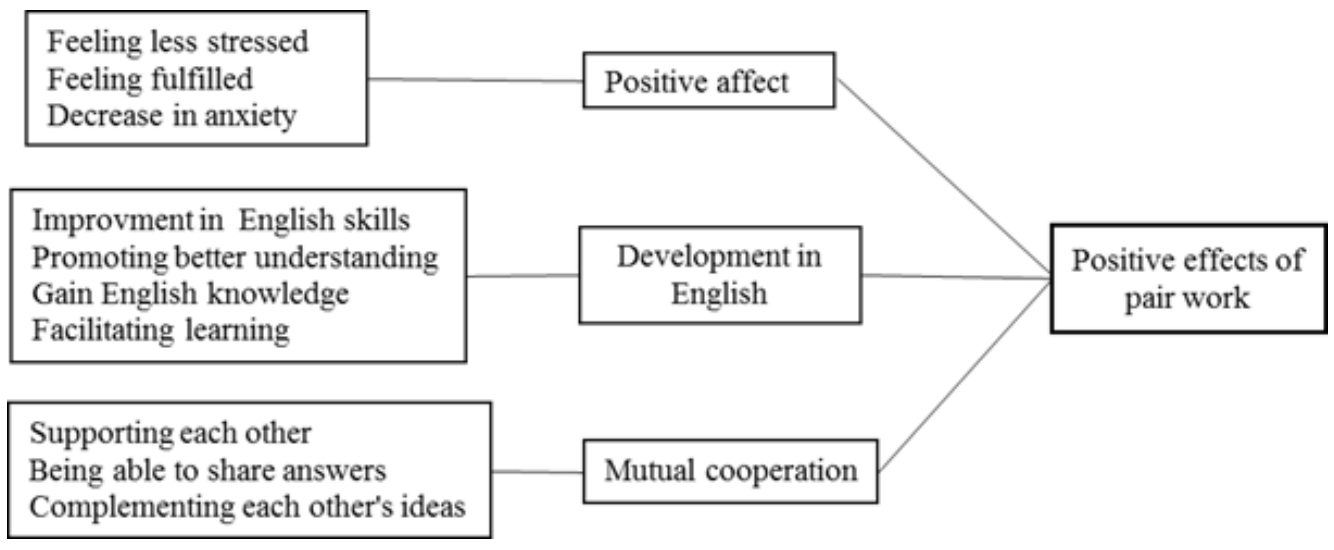

Fig. 2 Results of Pattern Coding Concerning Student Perceptions of Learning from Each Other.

"emotional stability", such as gaining a calm feeling before a presentation. Among all the subcategories, "increase in confidence from preparation" emerged as a pattern code. On the other hand, some students felt they were not confident in speaking to the class, despite sufficient preparation. These learners seemed to have "speaking anxiety," an anxious feeling that comes from a perceived low ability. Some of these students explained that they were starting to tremble or that their hands were shaking from nervousness as soon as they stood in the front. These are examples of stage fright, a feeling that cannot be coped with easily when making a presentation in public. Some of the students still had "lingering fear of public speaking," despite adequate preparation. This could be overcome by improving their communication ability in English and repeated practicing. 

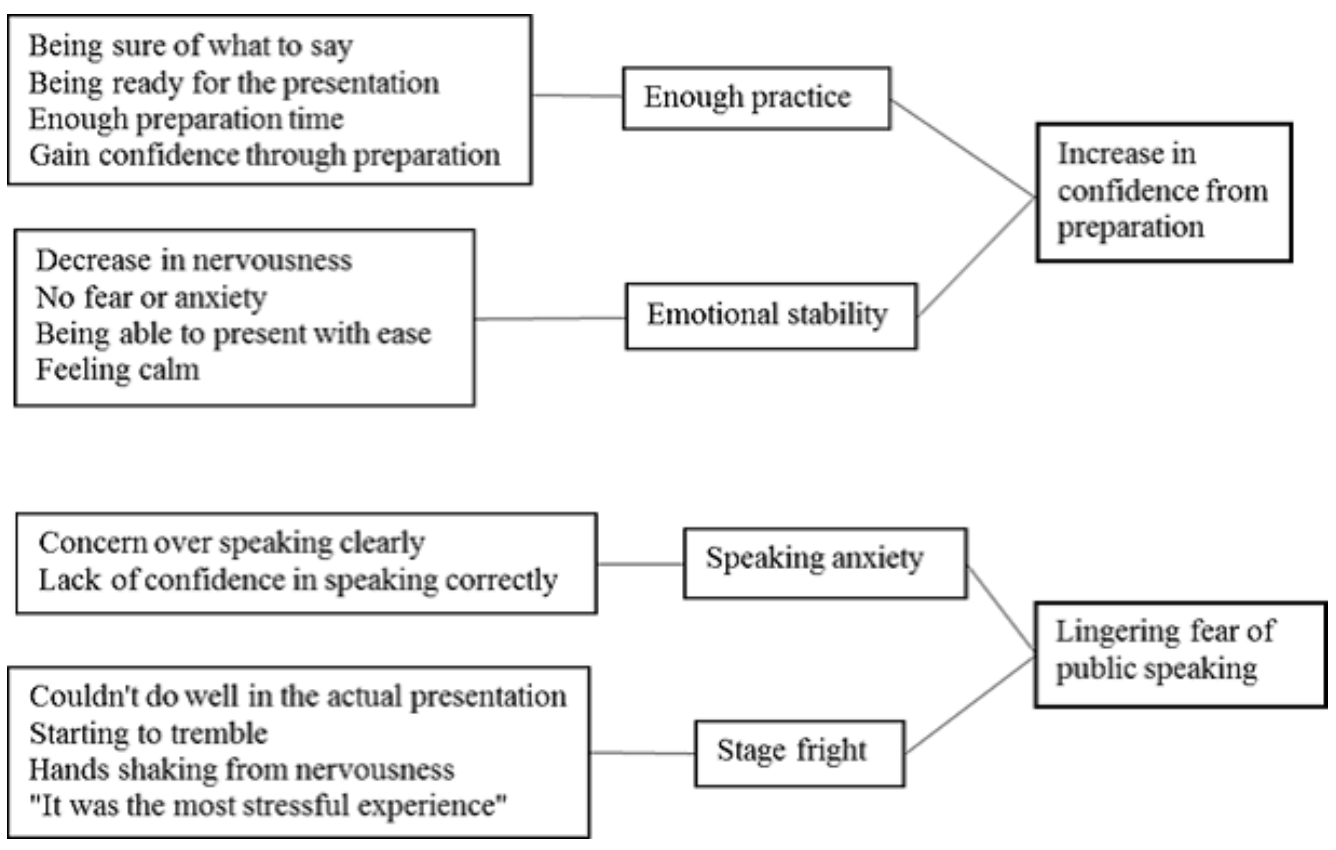

Fig. 3 Results of Pattern Coding Concerning Student Perceptions of Preparing before a Presentation.

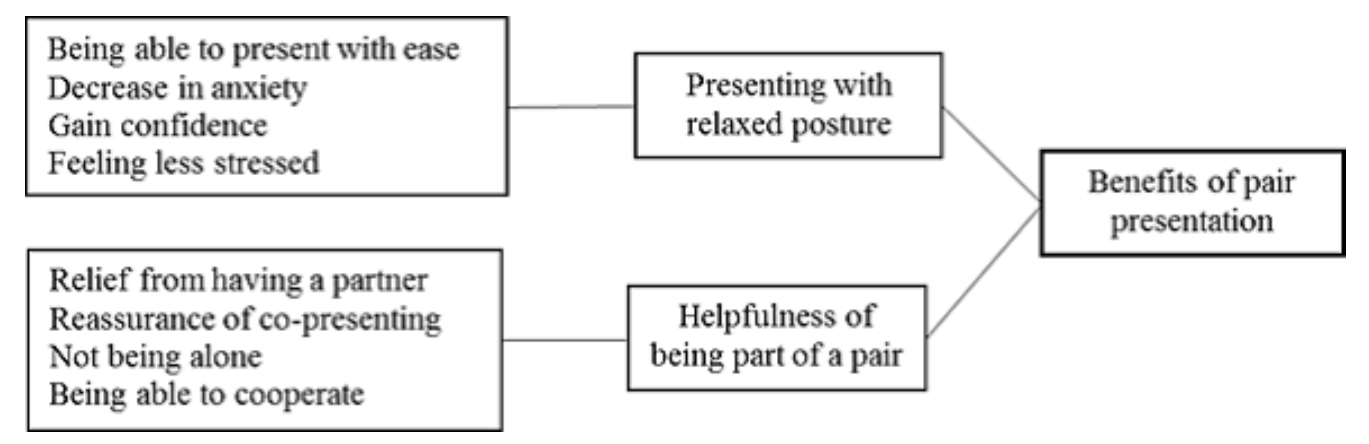

Fig. 4 Results of Pattern Coding Concerning Student Perceptions of Presenting in Pairs.

As shown in Fig. 4, students showed positive opinions about presenting in pairs. By having a partner, they were able to present with ease, gain more confidence and their anxiety decreased at the same time. They could "present with a relaxed posture," and they felt the "helpfulness of being part of a pair," such as the relief obtained from having a partner, the reassurance brought about by co-presenting and the sense of not being alone. These are the "benefits of pair presentation," which learners experienced in this classroom intervention.

Fig. 5 shows students' feedbacks on receiving individual support from the teacher. They realized the importance of consulting the teacher and, by asking the teacher for help, they could avoid feeling ashamed in front of their classmates. This indicates that students need the "alleviation of stress by the teacher." Moreover, students consider individual tutoring as the best way to solve a problem, and an effective way to promote understanding, therefore they are anxious to "learn with the teacher's help." Such opinions of 


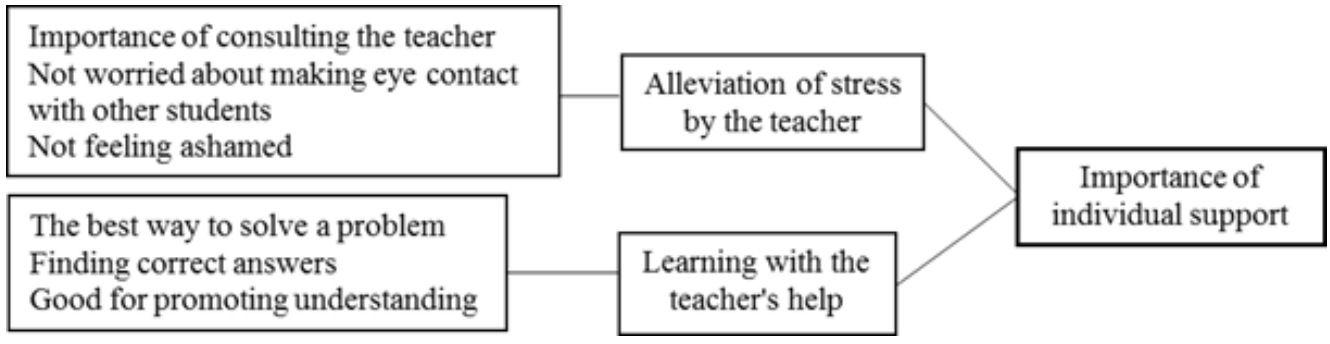

Fig. 5 Results of Pattern Coding Concerning Student Perceptions about Receiving Individual Support from the Teacher.

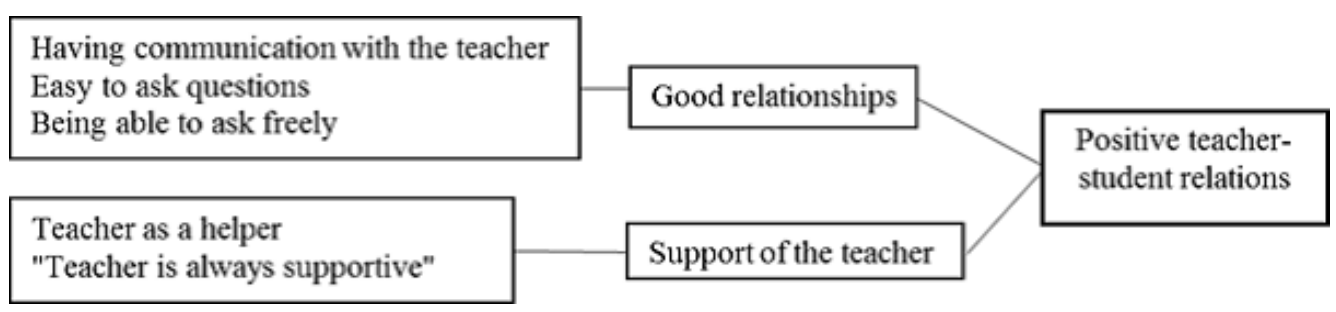

Fig. 6 Results of Pattern Coding for Student Perceptions of Relationships with the Teacher.

students show their awareness of the "importance of individual support."

Finally, as for students' perceptions of their relationships with the teacher (Fig. 6), they stressed that they could have good communication with the teacher if there was a pleasant mutual relationship. They felt that it is easier to ask questions in good class atmosphere and they won't hesitate to ask in that case. Furthermore, students viewed the teacher as a helper, who helps them in many situations, and they felt that the teacher was always supportive. Therefore, having "good relationships" and receiving the "support of the teacher" result in "positive teacher-student relations."

\section{Discussion}

This study investigated effective strategies for reducing language anxiety among Japanese EFL learners. RQ1 focused on the areas of language anxiety which were reduced due to the intervention in class. According to the analyses of two-way repeated measures ANOVA of the FLCAS, communication apprehension was found to decrease significantly in students in the experimental group compared to the control group. It is similar to the findings of Nagahashi's (2007) which showed that an intervention including pair work and group work could get rid of communication apprehension of students. However, Nagahashi could not obtain successful results in the reduction of the total items of communication apprehension and there was a lack of a control group. This study has put forward a further explanation of the efficacy of the intervention for reducing language anxiety and discovered communication apprehension as a factor greatly influenced by anxiety-reducing strategies.

RQ2 asked which strategies students felt to be the most effective in reducing language anxiety. Student 
responses to the ARSS (Fujii, 2015) were compared pre- and post-test. A paired t-test revealed two items to have a significant increase in mean scores, which indicates the perceived effectiveness of the strategies. Item 5, "I feel more relaxed when making presentations in small groups than by myself." had a significant increase in mean scores. As part of the intervention, pair presentation was carried out instead of individual presentation. Woodrow (2006) mentions that giving oral presentations and performing in front of classmates are two of the most stressful activities for anxious learners. Including pair-presentation was a new attempt as empirical research and its effectiveness was confirmed from the obtained results. Another item that showed a significant increase in mean score was Item 8, "Doing more small-group and pair work reduces my anxiety." This result is in agreement with Wu's (2010) findings, which showed that anxious learners who worry about making mistakes in front of the class felt less anxious when they were in a pair or group. Also, Crookall and Oxford (1991) state that teachers can improve the classroom climate through the use of pair work and group work, by creating a pattern of student-to-student communication. Students seemed to feel less anxious when they receive peer support, such as working together and teaching each other during classroom activities.

RQ3 asked what the students thought of the anxiety-reducing strategies implemented in this study. "Positive effects of pair work," "increase in confidence from preparation," "benefits of pair presentation," "importance of individual support," and "positive teacher-student relations" emerged from student answers to the open-ended post-survey questionnaire on the benefits of intervention. First, as for introducing pair work, students mainly stated its positive aspects. In addition to the advantages of promoting learning, students felt somewhat relieved by working in small groups rather than by working individually. Second, preparing before the presentation was effective for most of the students, but some still felt a "lingering fear of public speaking" in this study. According to Marwan (2008), lack of preparation is a major contributor to learner foreign language anxiety. Although the students in this study felt some anxiety in speaking-despite adequate preparations, if there had been no time spent on preparation, their anxiety would have been more serious. Third, pair presentations seemed to reduce learner anxiety. As having to speak or in front of others is a real anxiety-evoking situation (Young, 1990), it is very important to minimize anxiety in oral presentations by having students present in pairs or small groups. Fourth, students found it preferable to receive individual advice. Horwitz, Tallon, and Luo (2010) states, teachers should "help students reduce their anxiety levels by focusing both on the individual characteristics associated with anxiety and on the instructional factors that contribute to increased anxiety" (p.108). Teachers should be ready to help them overcome their problems in the classroom. Finally, maintaining a positive teacher-student relationship was found to be important, which corroborates the idea of Tsui (1996), who suggested that "establishing a good relationship with students is extremely important in creating a conducive learning atmosphere in the classroom" (p.164). Creating a bond of trust between students and the teacher makes it possible to reduce anxiety and promote a positive attitude among students toward classroom activities. As a whole, the strategies employed in this study were perceived as being beneficial in reducing learner feelings of anxiety. 


\section{Conclusions}

This study examined the effectiveness of strategies for reducing language anxiety through a quasiexperimental design. Communication apprehension was found to decrease as an outcome of an experimental intervention. Among the anxiety-reducing strategies utilized in this study, making a presentation in pairs, and doing pair work and group work were found to be especially effective in reducing learner anxiety. By cooperating and working together with classmates in classroom activities, students could feel more relaxed and less stressed. The advantages of pair work and pair presentations can be confirmed from the learner responses to the open-ended questionnaire as well, which stated their positive effect in working with a partner and the helpfulness of being one half of a pair when making presentations. In addition to receiving peer support, students also cited the importance of having the support of the teacher, which helped alleviate their stress in class. Adequate preparation before a presentation was effective in reducing most of the feelings of anxiety among the learners, but some of them said the fear of public speaking still remained to some extent. It is an important issue to have every student present in a less stressful manner.

There are some limitations to this study. First, the study used an open-ended questionnaire to ask for student perceptions of the intervention strategies. As the responses to the questionnaire were all written, it was not possible to delve deeply into learner opinions and their actual feelings underlying their ideas. Secondly, it is unfortunate that this study did not yield the result of significance in student overall anxiety levels between the experimental and control groups. However, the decrease in anxiety levels was stronger in the experimental group than in the control group. Communication apprehension was found to decrease significantly and, test anxiety was also marginally significant. The current findings add to a growing body of literature on how to minimize learner language anxiety in language classrooms.

Recognizing and addressing language anxiety helps students to be more responsive, and makes language learning a much more enjoyable experience (Tsui, 1996). To have students enjoy learning English without feelings of anxiety, it is important for teachers to utilize effective strategies for reducing language anxiety. This study has offered suggestions for dealing with students who have marked anxiety in English classrooms. Introducing effective strategies for reducing language anxiety will prove to be helpful for anxious learners, as well as their teachers in choosing appropriate instructional techniques for creating a less stressful classroom.

\section{References}

Alrabai, F., 2014. Reducing Language Anxiety and Promoting Learner Motivation: A Practical Guide for Teachers of English as a Foreign Language. Milton Keynes, UK: Lulu.

Alrabai, F., 2015. "The Influence of Teachers' Anxiety-reducing Strategies on Learners' Foreign Language Anxiety", Innovation in Language Learning and Teaching, Vol. 9, pp. 163-190.

Alsowat, H. H., 2016. "Foreign Language Anxiety in Higher Education: A Practical Framework for Reducing FLA", European Scientific Journal, Vol. 12, No. 7, pp. 193-220. 
Crookall, D. and Oxford, R., 1991. "Dealing with Anxiety: Some Practical Activities for Language Learners and Teacher Trainees", In E. K. Horwitz \& D. J. Young (Eds.), Language Anxiety: From Theory and Research to Classroom Implications (pp. 141-150). Englewood Cliffs, NJ: Prentice Hall.

Fujii, S., 2015. "A Conceptualization of Strategies for Reducing Students' Language Anxiety", HELES Journal, Vol. 15, pp. 3-19.

Gkonou, C., 2017. "Towards an Ecological Understanding of Language Anxiety". In C. Gkonou, M. Daubney and J-M. Dewaele (Eds.), New Insights into Language Anxiety: Theory, Research and Educational Implications (pp. 135-155). Bristol, UK: Multilingual Matters.

Horwitz, E. K., 2013. Becoming a Language Teacher: A Practical Guide to Second Language Learning and Teaching (2nd ed.). Boston, MA: Pearson.

Horwitz, E. K., 2017. "On the Misreading of Horwitz, Horwitz and Cope (1986) and the Need to Balance Anxiety Research and the Experiences of Anxious Language Learners" In C. Gkonou, M. Daubney \& JM. Dewaele (Eds.), New Insights into Language Anxiety: Theory, Research and Educational Implications (pp. 31-47). Bristol, UK: Multilingual Matters.

Horwitz, E. K., Horwitz, M. B. and Cope, J. A., 1986. "Foreign Language Classroom Anxiety", The Modern Language Journal, Vol. 70, No. 2, pp. 125-132.

Horwitz, E. K., Tallon, M. and Luo, H., 2010. "Foreign Language Anxiety", In J. C. Cassady (Ed.), Anxiety in Schools: The Causes, Consequences, and Solutions for Academic Anxieties (pp. 95-115). New York, NY: Peter Lang.

Kondo, D. S. and Yang, Y-L., 2004. "Strategies for Coping with Language Anxiety: The Case of Students of English in Japan", ELT Journal, Vol. 58, pp. 258-265.

MacIntyre, P. D., 2002. "Motivation, Anxiety and Emotion in Second Language Acquisition", In P. Robinson (Ed.), Individual Differences and Instructed Language Learning (pp. 45-68). Amsterdam, NL: John Benjamins Publishing.

MacIntyre, P. D. and Gardner, R. C., 1994. "The Subtle Effects of Language Anxiety on Cognitive Processing in the Second Language", Language Learning, Vol. 44, pp. 283-305.

Marwan, A., 2008. "The Exploration of Factors Triggering Foreign Language Anxiety: Learners' Voice", TEFLIN Journal, Vol. 19, pp. 119-126.

Nagahashi, T. L., 2007. "Techniques for Reducing Foreign Language Anxiety: Results of a Successful Intervention Study", Annual Research Report on General Education, Akita University, Vol. 9, pp. 53-60.

Saldaña, J., 2009. The Coding Manual for Qualitative Researchers. Los Angeles, CA: SAGE.

Sparks, R. L. and Patton, J., 2013. "Relationship of L1 Skills and L2 Aptitude to L2 Anxiety on the Foreign Language Classroom Anxiety Scale", Language Learning, Vol. 63, No. 4, pp. 870-895.

Tsiplakides, I. and Keramida, A., 2009. "Helping Students Overcome Foreign Language Speaking Anxiety in the English Classroom: Theoretical Issues and Practical Recommendations", International Education Studies, Vol. 2, pp. 39-44.

Tsui, A. B. M., 1996. "Reticence and Anxiety in Second Language Learning", In K. M. Bailey \& D. Nunan (Eds.), Voices from the Language Classroom: Qualitative Research in Second Language Education (pp. 
145-167). New York, NY: Cambridge University Press.

Woodrow, L., 2006. "Anxiety and Speaking English as a Second Language", RELC Journal, Vol. 37, pp. 308-328.

Wu, K-H., 2010. "The Relationship between Language Learners' Anxiety and Learning Strategy in the CLT Classroom", International Education Studies, Vol. 3, pp. 174-191.

Young, D. J., 1990. “An Investigation of Students' Perspectives on Anxiety and Speaking”, Foreign Language Annals, Vol. 23, pp. 539-553.

\section{Acknowledgement}

This paper was part of the author's doctoral dissertation, which was accepted by Hokkaido University on September 25th, 2017. The full paper is available from the following repository site: https://eprints. lib.hokudai.ac.jp/dspace/handle/2115/68550

\section{Appendix. The Foreign Language Classroom Anxiety Scale (FLCAS)}

\section{Items}

1. I never feel quite sure of myself when I am speaking in my English class.

2. I don't worry about making mistakes in the English class.

3. I tremble when I know that I'm going to be called on in the English class.

4. It wouldn't bother me at all to take more English classes.

5. During English class, I find myself thinking about things that have nothing to do with the course.

6. I keep thinking that the other students are better at English than I am.

7. I am usually at ease during tests in my English class.

8. I start to panic when I have to speak without preparation in the English class.

9. I worry about the consequences of failing my English class.

10. I don't understand why some people get so upset over English classes.

11. In the English class, I can get so nervous I forget things I know.

12. It embarrasses me to volunteer answers in my English class.

13. I would not be nervous speaking English with native speakers.

14. I get so upset when I don't understand what the teacher is correcting.

15. Even if I am well prepared for English class, I feel anxious about it.

16. I often feel like not going to my English class.

17. I feel confident when I speak in the English class.

18. I am afraid that my English teacher is ready to correct every mistake I make.

19. I can feel my heart pounding when I'm going to be called on in the English class.

20. The more I study for the English test, the more confused I get. 
21. I don't feel pressure to prepare very well for the English class.

22. I always feel that the other students speak English better than I do.

23. I feel very self-conscious about speaking English in front of other students.

24. The English class moves so quickly I worry about getting left behind.

25. I feel more tense and nervous in my English class than in my other classes.

26. I get nervous and confused when I am speaking in the English class.

27. When I'm on my way to the English class, I feel very sure and relaxed.

28. I get nervous when I don't understand every word the English teacher says.

29. I feel overwhelmed by the number of rules you have to learn to speak English.

30. I am afraid that the other students will laugh at me when I speak English.

31. I would probably feel comfortable around native speakers of English.

32. I get nervous when the English teacher asks questions which I haven't prepared in advance.

Note. All the expressions of "foreign language" in the original FLCAS (Horwitz et al., 1986) are modified into "English" in order to fit the contexts of the current study. 